\title{
Effect of ice pack application on pain intensity during active phase of the first stage of labor among primiparaous
}

\author{
Jilan Ibrahim Al-Battawi ${ }^{1}$, Noha Mohamed Mahmoud ${ }^{1}$, Rasha Mohamed Essa*2 \\ ${ }^{1}$ Faculty of Nursing, Alexandria University, Alexandria, Egypt \\ ${ }^{2}$ Faculty of Nursing, Damanhour University, Damanhour, Egypt
}

Received: April 5, 2017

DOI: $10.5430 /$ jnep.v8n2p35
Accepted: September 10, $2017 \quad$ Online Published: October 11, 2017

URL: https://doi.org/10.5430/jnep.v8n2p35

\begin{abstract}
Labor pain management is one of the main goals of maternity care. Ice application or cooling has been claimed to be as an effective, safe and non-invasive adjuvant mean for providing pain relief during the first stage of labor. Aim of the study: To evaluate effect of ice pack application on pain intensity during active phase of the first stage of labor among primiparaous. Research design: None-randomized-controlled clinical trial research design was utilized. Setting: The study was conducted at labor and delivery unit of El Shatby Maternity University Hospital affiliated to Alexandria University. Subjects: Convenience sample of 80 pregnant women attending the previously mentioned setting were recruited in the study. They were equally divided into ice application \& control groups. Tools: Three tools were used for data collection, namely: Tool (I): Pregnant women basic data structured interview schedule, Tool II: Visual Analogue pain intensity scale (VAS) \& Tool III: Present Behavioral Intensity Scale (PBIS) Tool IV: Satisfaction visual analogue scale (SVAS). A high statistically significant difference was observed between the study $\&$ control groups in relation to their pain intensity using VAS before and after the intervention $(P \leq .000)$. In addition, another high statistically significant difference was detected between the study group \& control groups in relation to their behavior of labor pain $(P=.000)$ before $\&$ after 30 as well as $60 \mathrm{~min}$ of intervention. Based on the study findings, it could be concluded that the application of ice pack application during active phase of first stage of labor appeared to have a remarkable effect on labor pain intensity. In service training programs for nurses in labor units about the utilization of non-pharmacological approaches is recommended.
\end{abstract}

Key Words: Labor pain, Ice application, Pain management

\section{INTRODUCTION}

Childbirth is dully considered a highly joyful experience and anxiety-provoking event in every woman's life. Generally, it is a meaningful and rewarding time for the woman and her family. It requires a woman to utilize all of her physical and psychological abilities for coping with this event. Global statistical reports ascertain that approximately 210 million women get pregnant each year worldwide. There are more than 130 million annual births worldwide, of which more than 4 million occur in the United States and nearly 120 million in less developed countries. In Egypt, the annual number of births constitutes 1,881 thousands according to United Nations Populations Fund (UNFPA) statistics in 2010. On the other hand, the birth rate is 23.18 births $/ 1,000$ populations Egypt.

*Correspondence: Rasha Mohamed Essa; Email: rashaessa111@yahoo.com; Address: Faculty of Nursing, Damanhour University, Damanhour, 
according to the World Bank report 2013. ${ }^{[1,2]}$

Labor and childbirth represents both an end and a beginning through transcendent event with meaning far beyond the actual physiologic process. Although labor is a natural phenomenon, yet labor pain is arguably one of the most severe types of pain a woman may endure in her life-time. It is a foremost concern for every pregnant woman since failure to relieve it might have a great impact on birth outcome. Severe labor pain also has been implicated in contributing to long term emotional stress with potential adverse consequences on maternal mental health and family relationship. In addition, it is one of the severest pains that cause many women request cesarean section for fear of pain. Meanwhile, mortality rate of $\mathrm{C} / \mathrm{S}$ is five times more than normal vaginal delivery. ${ }^{[3,4]}$

Pain in general, is defined by the International Association for the Study of Pain (IASP) as "an unpleasant sensory and emotional experience resulting from actual or potential tissue damage". Recent literature has emphasized the importance of pain and recommended it as the fifth vital sign. Labour pain is a complex and subjective interaction between multiple physical, psychosocial, environmental and cultural factors as well as a woman's interpretation of labour stimuli. It is a fluctuating cycle, appearing in waves, first peaking and then subsiding in turn. The frequency of this cycle increases as time for delivery nears. Pain during the first stage of labor is due to several causes including: a) visceral pain caused by uterine contractions, cervical dilation, and stretching of the adnexa and uterine ligaments; b) somatic pain due to the dilatation of the perineal plane, vagina and external genitals during the expulsion phase. Physiological responses to labour pain occur as a result of activation of the autonomic nervous system including: changes in blood pressure, heart rate, respiration, and metabolic responses. Behavioral cues such as; gross motor activity, verbal expressions and facial expressions. ${ }^{[5-7]}$

Labor pain in the first stage could be explained by the gatecontrol theory which is based on the premise that pain impulses travel through either small diameter or large diameter nerve cells, both of them pass through the same gate. Large-diameter cells have the ability, when properly stimulated, to close the gate and block transmission of the pain impulse to the brain. While, small diameter cells are slowly conducting A-delta and $\mathrm{C}$ fibers facilitates transmission of impulses leading to perception of pain (open the gate). Gate control theory provides framework that may explain the use of non-pharmacological methods of pain relief during labor pain. ${ }^{[8,9]}$

Pain management in labour is one of the main goals of maternity care. Two models for pain management are identified, medical and midwifery models. The former model adopts pharmacologic methods of pain relief, such as systematic analgesia or anesthesia. Pharmacologic approaches are invasive, and have the potential to cause side effects to both the mother and the fetus such as fatal debilitation of the central nervous system, a reduction in maternal cardiac output, bladder distension and prolongation of the second stage of labor as well as impeding women's active participant in giving birth. ${ }^{[10,11]}$

The later model (midwifery) utilizes the non-pharmacologic measures of pain relief which include: physical or psychological activities that divert the mother concentration away from pain. They also increase relaxation and pain threshold by cutting pain fear-tension cycle. These therapies are preferred over pharmacological methods because they are non-invasive, minimize complications for mother or fetus, provide support and enhance the satisfaction cooperation among mothers and their therapists. Non-pharmacological strategies include: therapeutic touch; walking; application of heat and cold compresses; transcutaneous electrical nerve stimulation (TENS); breathing techniques; imagery; acupuncture; acupressure; homoeopathy; reflexology and ice application. ${ }^{[12,13]}$

Ice application or cooling has been advocated as an effective, safe and non-invasive adjuvant means of providing pain relief during the first stage of labor. Many studies were carried out in the past decade to assess its effect on pain relief in general and labour pain in particular. Ice applied to an injured body part is used as standard treatment of trauma, bleeding, swelling, and soft tissue injuries. Moreover, ice application was effectively blocks nerve conduction especially in musculoskeletal pain. The researchers hypothesized that the efficacy of ice application was due to engaging the gate control pain system rather than eliminating the source of the pain. When impulses are reaching the spine pathway to the brain are stimulated by techniques such as vibration, scratching or ice application, the gate closes, resulting in a decrease in the sensation of pain. ${ }^{[14-17]}$

The mechanisms of pain relieve with ice pack application including inhibition of nociceptors, a reduction in muscle spasm and/or via the analgesic descending pathway of the central nervous system such as endorphins. Other relevant literatures pointed to the significant role of the ice pack application reduce pain through excretion of endorphin, inhibit diffusion of harmful materials and reducing pain receptors sensitivity. In addition, this method increases pain threshold and reduces the sensory and motor nerves conduction velocity. Moreover, cold signals are transferred to the spinal cord through A Delta fibers instead of C fibers. Impulses transmitted through thick fibers (A-Delta fibers), close the 
pain gate and thus decrease pain. When thick fibers' impulses are stimulated synthetically by ice, the gate closes further (i.e. the gate control theory of pain). Consequently, ice application may help to manage labour pain. ${ }^{[18-21]}$ A study was conducted by Merlin Golda et al. (2016) ${ }^{[22]}$ about the effectiveness of cold application on pre-procedure (AV fistula puncture) pain among hemodialysis patients in tertiary care hospital. The study finding reveals that the subjective pain scores were found to be significantly $(P=.01)$ reduced within the experimental group by cold application. This study highlights the need for adopting the alternative methods for reducing the pain at AV fistula cannulation site in health care settings. Another, a single-blind randomized clinical trial was done by Vaishali R Sinha et al. (2015) ${ }^{[23]}$ about effects of cold application on pain \& anxiety during chest tube removal among postoperative cardiac surgery adult patients in India. They indicated that the cold application on chest tube removal was effective in reducing pain and anxiety among postoperative cardiac surgery patient. Cold application is simple, cheap, non-pharmacological anxiety and pain management strategy ensuring good results. Furthermore, de Souza Bosco Paiva C, et al. (2015) ${ }^{[24]}$ who conducted study about Length of perineal pain relief after ice pack application in Brazil they concluded that ice pack application for 20 min is effective for alleviating postpartum perineal pain and continues to be effective between $1 \mathrm{~h} 35 \mathrm{~min}$ for up to $2 \mathrm{~h}$.

Although literature had hinted to the effect of ice application on pain intensity during labor, yet evidence-based research are still inadequate in this respect. Accordingly this study was greed to evaluate effect of ice pack application on pain intensity during labor, in order to help in updating as well as enhancing the body of knowledge for the nursing field and improve nursing practices, which will ultimately contribute to the optimal women and infant's health and safety.

\subsection{Aim of the study}

This study aims to evaluate effect of ice pack application on pain intensity during active phase of the first stage of labor among primiparaous.

\subsection{Research hypothesis}

Laboring women who receive ice pack application exhibit less labor pain intensity than those who do not receive it.

\section{MATERIALS AND METHOD}

\subsection{Research design}

This is a none-randomized controlled clinical trial research design, where effect of ice pack application (independent variable) on intensity of pain during the first stage of labor (dependent variables) was examined. Both manipulation and control were utilized.

\subsection{Setting}

The study was conducted at labor and delivery unit of El Shatby Maternity University Hospital affiliated to Alexandria University. It receives clients from Alexandria as well as adjacent governorates namely: Elbehera, et al.

\subsection{Subjects}

According to Epi info 7 program sample size estimation program a convenience sample of 80 pregnant women out of 450 (representing the average number of women attending the previously mentioned setting during the last three months prior to the study) were recruited in the study. The study subjects were selected through a non-probability sampling technique.

\subsection{Inclusion criteria}

Women who have normal and full term pregnancy, in active phase of the first stage of normal onset of labor, free from chronic diseases, didn't receive any pharmacological pain relief substance and willing to participate in the study was included in the study. The subjects (80) were equally assigned to either one of two groups:

- Group 1: The study group, which consisted of 40 women upon whom ice pack was applied.

- Group 2: The control group, which comprised the remaining 40 women who received routine hospital care.

\subsection{Tools}

Three tools were used for data collection.

Tool I: Subjects' basic data structured interview schedule This tool was developed by the researcher. It entailed the following three parts: First part, women socio-demographic characteristics (age, level of education, occupation, marital status, residence \& family type); Second part, women's history/nature of current pregnancy (gravidity, number of abortion, pregnancy whether was planned or not, weeks of gestation, number of antenatal visit); Third part, history of current labour: date \& time of onset of labour, uterine contractions (duration, frequency and interval), condition of the membranes and presence of show.

\section{Tool II: Visual analogue pain intensity scale (VAS)}

This tool was originally developed by Melzac and Katz $(1994)^{[25]}$ to estimate the subjective level of pain intensity. It is a ten-point numerical scale consisting of $10 \mathrm{~cm}$ horizontal straight line ranging from $0-10 \mathrm{~cm}$ with words "no pain" on the left which denotes the least pain and "unbearable" on 
the right which denotes the worst pain. Pain intensity is evaluated by asking the women to point on the line a mark $\&$ then it is measured in cm from the "no pain" end to obtain the woman's score. This number represents the intensity of their pain. Descriptive terms are used as follows: No pain (0), Mild pain (1-3 cm), Moderate pain (4-6 cm), Severe pain $(7-9 \mathrm{~cm})$, and finally $(10 \mathrm{~cm})$ Unbearable pain.

\section{Tool III: Present behavioral intensity scale (PBIS)}

This scale was originally developed \& validated by Bonnel $\&$ Bourrea (1985) ${ }^{[26]}$ and translated into Arabic language by the researchers to measure the present manifestations of pain. The PBIS is a five category behavioral observation scale with (0) representing normal respiration; (1) the frequency of amplitude of respiratory changes during contractions; (2) grasping reactions that cease during contraction/relaxation; (3) gasping that persists between contractions; and (4) signs of agitation. The level of pain in this measure is divided into 5 levels, with the score ranging from 0 to 4 . The higher score reflected the higher level of pain.

\section{Tool IV: Satisfaction visual analogue scale (SVAS)}

This tool was adopted from Brokelman et al. (2012) ${ }^{[27]}$ to estimate the subjective level of mothers' satisfaction. It is a ten-point numerical scale consisting of straight line ranging from $0-10 \mathrm{~cm}$. At the beginning and at the end, there are two descriptors representing extremes of satisfaction (i.e. no satisfaction and high satisfaction). The mother rated her satisfaction by making a vertical mark on the $10 \mathrm{~cm}$ line. Descriptive terms are used as follows no satisfaction (zero), mild satisfaction $(1-3 \mathrm{~cm})$, moderate satisfaction $(4-7 \mathrm{~cm})$ and high satisfaction $(8-10 \mathrm{~cm})$.

\subsection{Procedures}

The study was executed according to the following steps:

(1) An official letter from the Faculty of Nursing was forwarded to the director of El-Shatby Maternity University hospital to take his permission to collect data after explaining the purpose of the study.

(2) Tool 1 was developed by the researchers after extensive review of recent and related literature.

(3) Tool II \& III (to measure the intensity and the present manifestations of labor pains) respectively were adopted and translated to Arabic language by the researchers.

(4) The tools were validated by a jury of five experts in the related field.

(5) Tool's reliability was tested by cronbach's alpha test and the result was satisfactory $87 \%$.

(6) A pilot study was carried out on 8 parturients (excluded from the study subjects) from the previously mentioned settings to assure feasibility of the study, clarity and applicability of the tools and to identify obstacles that might interfere with the process of data collection. Tools were modified accordingly prior to data collection.

(7) For each recruited subject the following issues were considered: securing the subject's informed consent, keeping her privacy and right to withdraw at any time as well as assuring confidentiality of her data.

(8) The first 40 parturients who met the same criteria for inclusion in the study were recruited as the control group. Where each woman received the routine hospital care in addition to researchers' physical presence. The researchers dealt with each woman during each routine hospital procedure as insertion of I.V. fluids, enema, and providing hygienic care. Answering any question and the same baselines and following up assessments were conducted as study group.

(9) Then the following 40 parturients who met the criteria for inclusion in the study were recruited as the study group. Where each woman was individually interviewed during early labor.

(10) Each woman of both groups was individually interviewed during their active phase $(4-7 \mathrm{~cm}$ cervical dilatation) of the first stage of labor. Tools (I) \& (II) were used to collect the basic data \& pain intensity as well as behavioral responses to pain at that time (first assessment).

(11) The researchers, then, stayed with each women till the end of the first stage of labor, approximately 6-8 hours. During this time the ice gel pack was applied.

(12) In cold therapy group, ice gel pack application covered by a towel was put over the back and lower parts of the abdomen for 10 minutes throughout the contractions since initiation of active phase and this process repeated for 20 minutes every an hour (i.e. in order to allow the tissue to return to normal body temperature) up till full cervical dilatation later. Throughout the rest period between each application, mothers were asked to take the appropriate position for them. ${ }^{[28]}$

(13) For the both group after each session, tools II \& III \& IV were re-used immediately, 30 minutes and 60 minutes for pain reassessment (second time). The difference between the first and second time pain assessments for each woman in each group was calculated. Then these differences were compared among the two groups to identify the ice application effectiveness.

(14) Data were collected three days per week over a period of four months, started from the beginning of June till the end of September 2016. The average number of 
interviewee per week 3-4.

(15) Statistical analysis was done after collection of data by using Statistical Package for Social Sciences (SPSS) version 16 . Descriptive and analytical statistics were used such as percentages, means and standard deviations. Chi-square-test $\&$ Fisher Exact-test with a $P$ value was set at .05 to identify statistical significance difference between the results.

\section{RESUlts}

According to Table 1, it was clear that more than one-half $(52.00 \%) \&$ two-fifths $(40.00 \%)$ of the study and the control groups, respectively were less than 25 years. About onefifth $(22.5 \%)$ of both groups were primary or preparatory school graduates. Where $90 \%$ and $65 \%$ of the study and the control groups respectively, were housewives. An equal percent $(85 \%)$ of both groups were urban residents. The majority (90\%) of the study group lived in nuclear families compared to only $64.1 \%$ of the control group. More than one half $(67.5 \%$ \& $56.4 \%)$ of both groups, respectively perceived their income as adequate.

Table 1. Number \& percent distribution of the study subjects according to their socio-demographic characteristics

\begin{tabular}{|c|c|c|c|c|}
\hline \multirow{2}{*}{$\begin{array}{l}\text { Subject's } \\
\text { Socio-demographic } \\
\text { Characteristics }\end{array}$} & \multicolumn{2}{|c|}{$\begin{array}{l}\text { Ice application } \\
(\mathrm{N}=\mathbf{4 0})\end{array}$} & \multicolumn{2}{|c|}{$\begin{array}{l}\text { Control } \\
(\mathrm{N}=40)\end{array}$} \\
\hline & $\mathbf{n}$ & $\%$ & $\mathbf{n}$ & $\%$ \\
\hline \multicolumn{5}{|l|}{ Age } \\
\hline$<25$ & 21 & 52.5 & 16 & 40.0 \\
\hline $25-<30$ & 11 & 27.5 & 19 & 47.5 \\
\hline$\geq 30$ & 8 & 20.0 & 5 & 12.5 \\
\hline \multicolumn{5}{|l|}{ Level of education } \\
\hline Illiterate/read \& write & 5 & 12.5 & 18 & 45.0 \\
\hline Primary/preparatory school & 9 & 22.5 & 9 & 22.5 \\
\hline Secondary school & 17 & 42.5 & 13 & 32.5 \\
\hline University & 9 & 22.5 & 0 & 0.0 \\
\hline \multicolumn{5}{|l|}{ Occupation } \\
\hline Worker & 2 & 5.0 & 10 & 25.0 \\
\hline Employee & 2 & 5.0 & 4 & 10.0 \\
\hline House wife & 36 & 90.0 & 26 & 65.0 \\
\hline \multicolumn{5}{|l|}{ Current residence } \\
\hline Rural & 6 & 15.0 & 6 & 15.0 \\
\hline Urban & 34 & 85.0 & 34 & 85.0 \\
\hline \multicolumn{5}{|l|}{ Type of family } \\
\hline Nuclear & 36 & 90.0 & 25 & 64.1 \\
\hline Extended & 4 & 10.0 & 14 & 35.9 \\
\hline \multicolumn{5}{|l|}{ Family income } \\
\hline Enough & 27 & 67.5 & 22 & 56.4 \\
\hline Not enough & 13 & 32.5 & 17 & 43.6 \\
\hline
\end{tabular}

According to Table 2, it was observed that more than two fifths $(45 \%)$ of the study and control groups were primi- gravida. Substantial proportions $(86.36 \%$ and $68.18 \%)$ of the study group and the control groups had history of one abortion. Nearly, three quarters \& more (75\% and $82 \%$ ) of the study and the control groups, respectively, had attended four or more antenatal visit. A similar percentage (82.5\%) of study \& control groups had wanted/planned pregnancy.

Table 2. Number \& percent distribution of the study subjects according to their reproductive and current pregnancy history

\begin{tabular}{|c|c|c|c|c|}
\hline \multirow[t]{2}{*}{ Reproductive history } & \multicolumn{2}{|c|}{$\begin{array}{l}\text { Ice application } \\
(\mathrm{N}=\mathbf{4 0})\end{array}$} & \multicolumn{2}{|c|}{$\begin{array}{l}\text { Control } \\
(N=40)\end{array}$} \\
\hline & $\mathbf{n}$ & $\%$ & $\mathbf{n}$ & $\%$ \\
\hline \multicolumn{5}{|l|}{ Gravidity } \\
\hline Primigravida & 18 & 45.0 & 18 & 45.0 \\
\hline Multigrvida & 22 & 55.0 & 22 & 55.0 \\
\hline \multicolumn{5}{|c|}{ Number of abortion $(N=22)$} \\
\hline Once & 19 & 86.4 & 15 & 68.2 \\
\hline Twice & 3 & 13.6 & 7 & 31.8 \\
\hline \multicolumn{5}{|l|}{ Weeks of gestation } \\
\hline$<37$ weeks & 8 & 20.0 & 10 & 25.0 \\
\hline$\geq 37$ weeks & 32 & 80.0 & 30 & 75.0 \\
\hline \multicolumn{5}{|c|}{ Number of antenatal visits } \\
\hline$<4$ visits & 10 & 25.0 & 7 & 17.5 \\
\hline$\geq 4$ visits & 30 & 75.0 & 33 & 82.5 \\
\hline \multicolumn{5}{|c|}{ Wanted/planned pregnancy } \\
\hline Yes & 33 & 82.5 & 33 & 82.5 \\
\hline No & 7 & 17.5 & 7 & 17.5 \\
\hline
\end{tabular}

Table 3 portrays number and percent distribution of the study and the control groups according to their history of current labor. More than one half $(57.6 \% \& 62.5 \%)$ of the study $\&$ the control groups, respectively, reported that their labor started one day ago. More than three quarters ( $77 \%$ and $80 \%$ ) of the study and control groups, respectively their uterine contractions repeated twice every ten minutes. Table 3 also revealed that one-half \& more $(50 \% \& 55 \%)$ of the study and the control groups, respectively, had their uterine contractions every four to five minutes. Membrane was raptured $50 \%$ in the study compared to and $77.5 \%$ of control groups.

The Figure 1 reveals that $35 \%$ of the study group had severe labor pain before intervention. This percent had dropped to zero percent immediately and 30 minutes after ice application. However, it is interesting to notice that none of the subjects $(0 \%)$ who had mild labor pain before the intervention had accelerated to $80 \%$ immediately after intervention, then declined to as much as $45 \% \& 25 \%$ after $30 \& 60 \mathrm{~min}-$ utes after ice application. There was a statistically significant difference among study group in relation to their labor pain intensity using VAS before and immediately and after 30 
minutes as well as 60 minutes of ice application where $(P=$ $.0001)$.

Figure 2 portrays labor pain intensity using VAS among control group before \& after intervention. Slightly less than three fifths $(58.3 \%)$ of the control group had severe labor pain before intervention. This percent increased to $(72.5 \%$ \& $85 \%$ ) among control group, respectively immediately as well as after 60 minutes after intervention. There was no a statistically significant difference among control group regarding their labor pain intensity using VAS before and immediately as well as $30 \& 60$ minutes after intervention, where $P=$ .085 .

Table 4 clarifies the number and percent distribution of the study and the control groups according to their intensity of labor pain as measured by Visual Analogue Scale (VAS) before and after ice application. The table clearly reveals that all women of the study and control groups experienced labor pains of different intensity before intervention. Slightly less than two thirds $(62.5 \%)$ of the study group complained moderate labor pain compared to $44.5 \%$ of the control group. While severe pain was experienced by more than one-third (35\%) of the study group. This percent decreased to $0 \% \mathrm{im}-$ mediately \& after 30 minutes after intervention. This is compared to $58.3 \%, 72.5 \%$ \& $50 \%$ among the control group who had experienced such severe pain before and immediately as well as after 30 minutes, respectively. A highly statisti- cally significant difference was observed among women of the study \& control groups in relation to their pain intensity using VAS before and after intervention, where $P \leq .000$.

Table 3. Number and percent distribution of the study subjects according to their history of current labor

\begin{tabular}{|c|c|c|c|c|}
\hline \multirow{2}{*}{$\begin{array}{l}\text { History of current } \\
\text { labor }\end{array}$} & \multicolumn{2}{|c|}{$\begin{array}{l}\text { Ice application } \\
(\mathrm{N}=\mathbf{4 0})\end{array}$} & \multicolumn{2}{|c|}{$\begin{array}{l}\text { Control } \\
(\mathrm{N}=40)\end{array}$} \\
\hline & $\mathbf{n}$ & $\%$ & $\mathbf{n}$ & $\%$ \\
\hline \multicolumn{5}{|l|}{ Onset of labor pain } \\
\hline Less one day & 17 & 42.5 & 15 & 37.5 \\
\hline One day & 23 & 57.5 & 25 & 62.5 \\
\hline \multicolumn{5}{|c|}{ Number of contraction/10 minutes } \\
\hline Once & 0 & 0.0 & 5 & 12.5 \\
\hline Twice & 31 & 77.5 & 32 & 80.0 \\
\hline Three times & 9 & 22.5 & 3 & 7.5 \\
\hline \multicolumn{5}{|c|}{ Duration of contraction in seconds } \\
\hline $20-<40$ & 21 & 52.5 & 29 & 72.5 \\
\hline$\geq 40$ & 19 & 47.5 & 11 & 27.5 \\
\hline \multicolumn{5}{|c|}{ Interval between contraction } \\
\hline 2 & 8 & 20.0 & 4 & 10.0 \\
\hline 3 & 10 & 25.0 & 16 & 40.0 \\
\hline $4-5$ & 22 & 55.0 & 20 & 50.0 \\
\hline \multicolumn{5}{|c|}{ Condition of membranes } \\
\hline Intact & 20 & 50.0 & 9 & 22.5 \\
\hline Ruptured & 20 & 50.0 & 31 & 77.5 \\
\hline
\end{tabular}

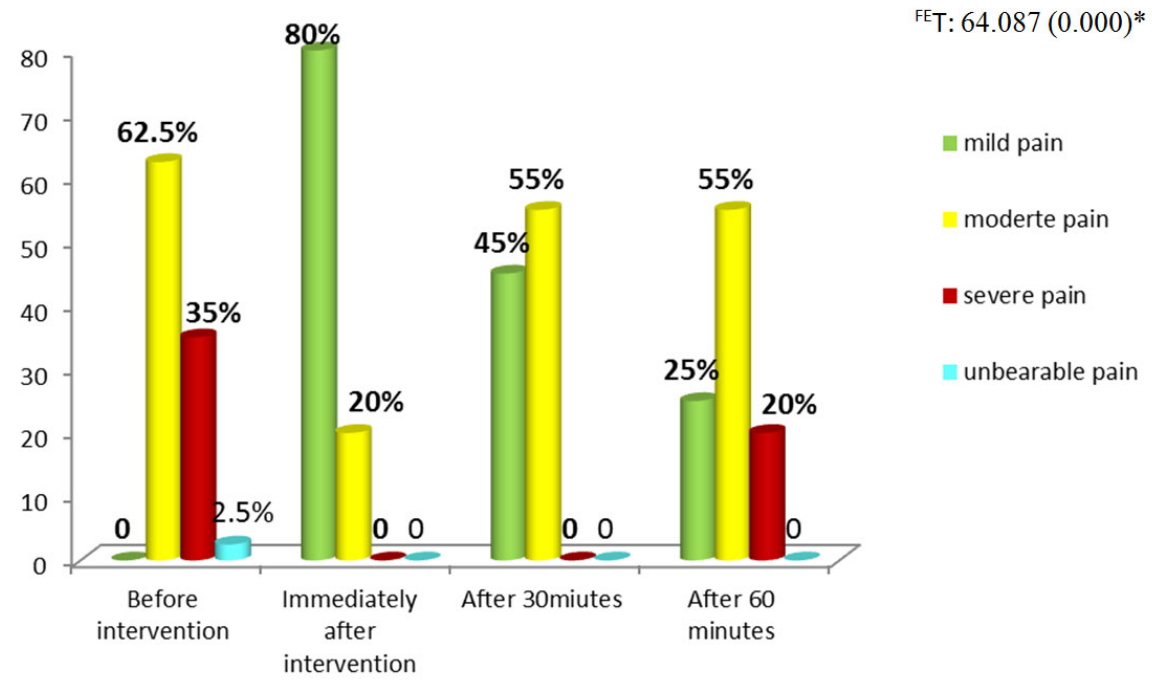

Figure 1. Number and percent distribution of the study group according to their intensity of labor pain using VAS before and after intervention

Figure 3 presents number and percent distribution of the study group according to their intensity of labor pain using PBIS before and after intervention. It was obvious that before the intervention almost equal proportions $(27.5 \% \& 17.5 \%)$ of them had intensity (3) \& (4). While immediately \& 30 minutes after the intervention-none of the subjects had either intensity (3) or (4). Although only $15 \%$ of the study group had intensity (1) before intervention, yet it raised to $(20 \%$, 
$72.5 \%$ \& 20\%) immediately as well as $30 \& 60$ minutes after before and immediately as well as $30 \& 60$ minutes after ice intervention, respectively. There was a statistically signif- application where $(P=.000)$.

icant difference regarding labor pain intensity using PIMS

FET: $14.533(0.085)$

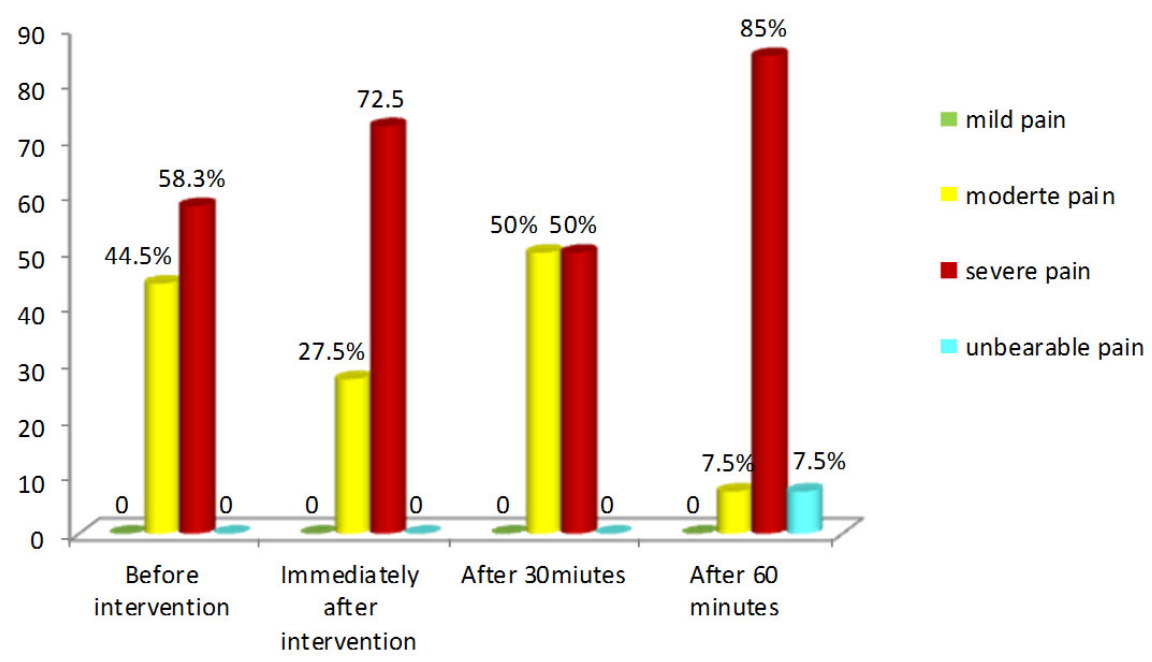

Figure 2. Number and percent distribution of the control group according to their intensity of labor pain using VAS before and after intervention

Table 4. Number and percent distribution of the study and the control groups according to their intensity of labor pain using VAS before and after intervention

\begin{tabular}{|c|c|c|c|c|c|c|c|c|c|c|c|c|c|c|c|c|}
\hline \multirow{3}{*}{ Level of pain } & \multicolumn{4}{|c|}{ Before intervention } & \multicolumn{4}{|c|}{$\begin{array}{l}\text { Immediately after } \\
\text { intervention }\end{array}$} & \multicolumn{4}{|c|}{ After 30miutes } & \multicolumn{4}{|c|}{ After 60 minutes } \\
\hline & \multicolumn{2}{|c|}{ Study } & \multicolumn{2}{|c|}{ Control } & \multicolumn{2}{|c|}{ Study } & \multicolumn{2}{|c|}{ Control } & \multicolumn{2}{|c|}{ Study } & \multicolumn{2}{|c|}{ Control } & \multicolumn{2}{|c|}{ Study } & \multicolumn{2}{|c|}{ Control } \\
\hline & $\mathbf{n}$ & $\%$ & $\mathbf{n}$ & $\%$ & $\mathbf{n}$ & $\%$ & $\mathbf{n}$ & $\%$ & $\mathbf{n}$ & $\%$ & $\mathbf{n}$ & $\%$ & $\mathbf{n}$ & $\%$ & $\mathbf{n}$ & $\%$ \\
\hline Mild pain & 0 & 0.0 & 0 & 0.0 & 32 & 80.0 & 0 & 0.0 & 18 & 45.0 & 0 & 0.0 & 10 & 25.0 & 0 & 0.0 \\
\hline Moderate pain & 25 & 62.5 & 19 & 44.5 & 8 & 20.0 & 11 & 27.5 & 22 & 55.0 & 20 & 50.0 & 22 & 55.0 & 3 & 7.5 \\
\hline Severe pain & 14 & 35.0 & 21 & 58.3 & 0 & 0.0 & 29 & 72.5 & 0 & 0.0 & 20 & 50.0 & 8 & 20.0 & 34 & 85.0 \\
\hline Unbearable pain & 1 & 2.5 & 0 & 0.0 & 0 & 0.0 & 0 & 0.0 & 0 & 0.0 & 0 & 0.0 & 0 & 0.0 & 3 & 7.5 \\
\hline Test of significance & \multicolumn{4}{|c|}{$2.581(.275)$} & \multicolumn{4}{|c|}{$61.474(.000)^{*}$} & \multicolumn{4}{|c|}{$38.095(.000)^{*}$} & \multicolumn{4}{|c|}{$43.535(.000)^{*}$} \\
\hline
\end{tabular}

Note. $\chi^{2}(P)$ : Chi-Square Test $\& P$ for $\chi^{2}$ Test; FET $(P)$ : Fisher Exact Test $\& P$ for FET-Test. *: Significant at $P \leq .05$

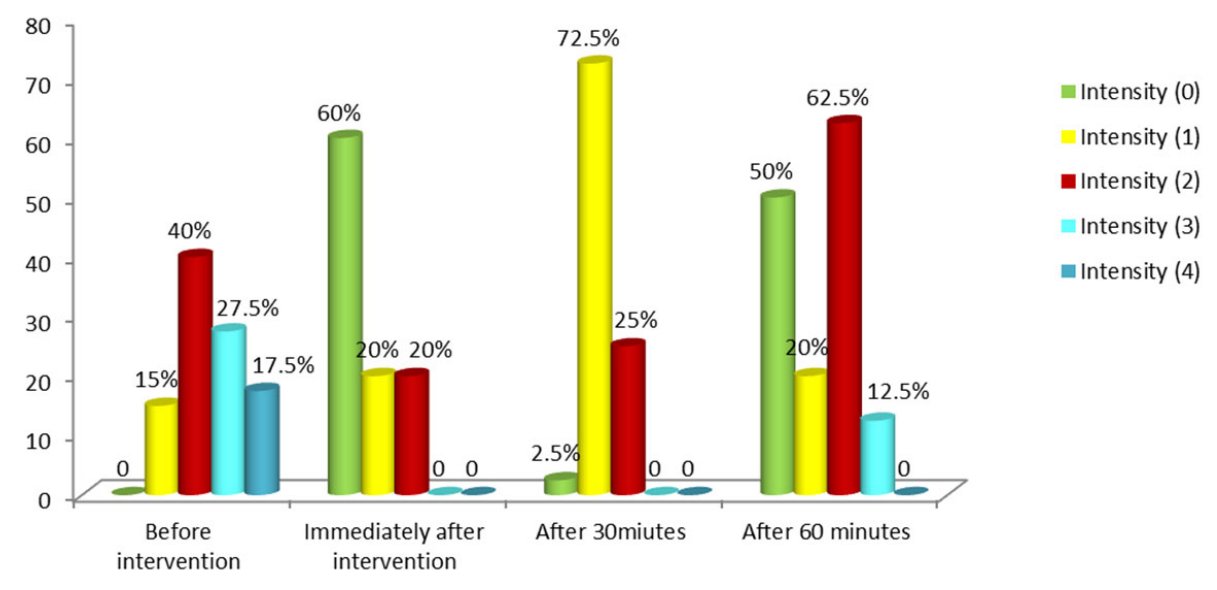


Figure 3. Number and percent distribution of the study group according to their intensity of labor pain using PBIS before and after intervention

Figure 4 reflects number and percent distribution of the control group according to their intensity of labor pain using PBIS before and after intervention. It shows that $10 \%$ of control had intensity (4) of pain level. Then this percent was dropped to $5 \%$ immediately after intervention. Then after 30
\& 60 minutes of intervention the percent jumped to $40 \%$ of control group. There was no a statistically significant difference regarding labor pain intensity using PIMS before and immediately as well as $30 \& 60$ minutes after intervention where $P=.378$.

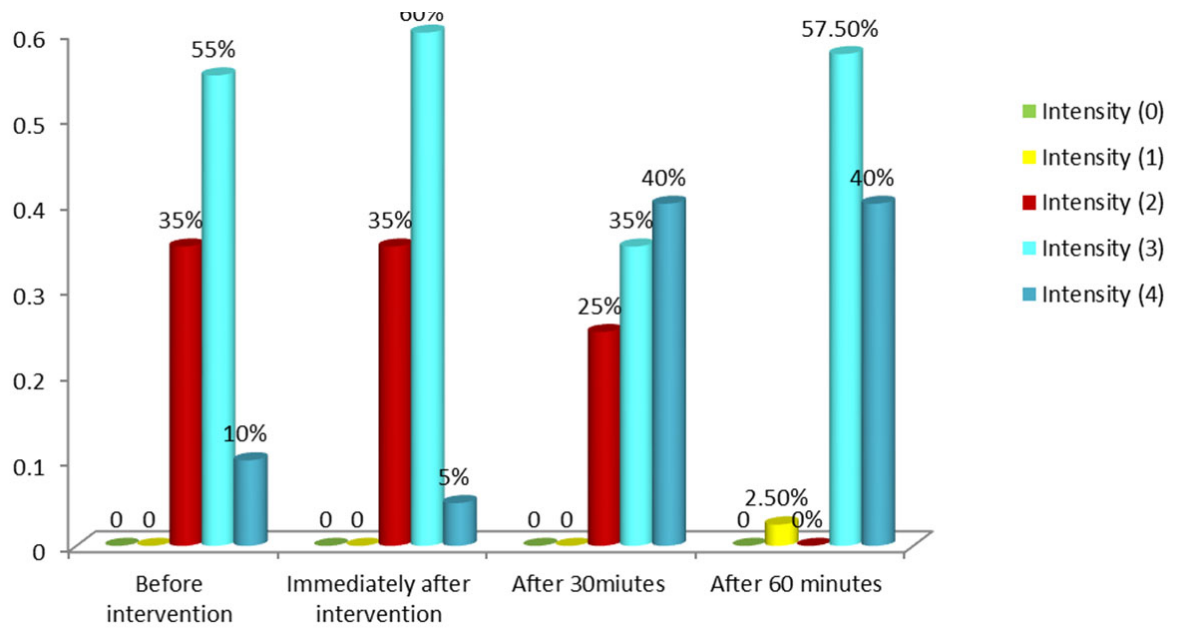

Figure 4. Number and percent distribution of the control group according to their intensity of labor pain using PBIS before and after intervention

Table 5 explicates the number and percent distribution of the study and the control groups according to their intensity of labor pain as measured by PBIS. Before intervention both groups had less similar behavior scores. Immediately and after $30 \& 60$ minutes of intervention, intensity (4) dropped sharply from $17.5 \%$ to $0 \%$ among ice application, while it increased from $10 \%$ to $40 \%$ among the control group after 30 $\& 60$ minutes. Intensity (3) also declined dramatically from $27.5 \%$ to $0 \%$ among the former, while it increased slightly from $55 \%$ to $60 \%$ \& then decreased to $35 \%$ among the latter immediately \& 30 minutes after ice application. Although none of the two groups had intensity (0) before intervention, yet immediately after intervention intensity (0) was $60 \%$ for the study group, compared to none of the control group. A highly statistically significant difference was noticed between the study \& control groups before and immediately as well as after $30 \& 60$ minutes of intervention, where $P=$ .000 .

Table 5. Number and percent distribution of the study and the control groups according to their intensity of labor pain using PBIS before and after intervention

\begin{tabular}{|c|c|c|c|c|c|c|c|c|c|c|c|c|c|c|c|c|}
\hline \multirow{3}{*}{ Level of pain } & \multicolumn{4}{|c|}{ Before intervention } & \multicolumn{4}{|c|}{$\begin{array}{l}\text { Immediately after } \\
\text { intervention }\end{array}$} & \multicolumn{4}{|c|}{ After 30 miutes } & \multicolumn{4}{|c|}{ After 60 minutes } \\
\hline & \multicolumn{2}{|c|}{ Study } & \multicolumn{2}{|c|}{ Control } & \multicolumn{2}{|c|}{ Study } & \multicolumn{2}{|c|}{ Control } & \multicolumn{2}{|c|}{ Study } & \multicolumn{2}{|c|}{ Control } & \multicolumn{2}{|c|}{ Study } & \multicolumn{2}{|c|}{ Control } \\
\hline & $\mathbf{n}$ & $\%$ & $\mathbf{n}$ & $\%$ & $\mathbf{n}$ & $\%$ & $\mathbf{n}$ & $\%$ & $\mathbf{n}$ & $\%$ & $\mathbf{n}$ & $\%$ & $\mathbf{n}$ & $\%$ & $\mathbf{n}$ & $\%$ \\
\hline Intensity (0) & 0 & 0.0 & 0 & 0.0 & 24 & 60.0 & 0 & 0.0 & 1 & 2.5 & 0 & 0.0 & 2 & 5.0 & 0 & 0.0 \\
\hline Intensity (1) & 6 & 15.0 & 0 & 0.0 & 8 & 20.0 & 0 & 0.0 & 29 & 72.5 & 0 & 0.0 & 8 & 20.0 & 1 & 2.5 \\
\hline Intensity (2) & 16 & 40.0 & 14 & 35.0 & 8 & 20.0 & 14 & 35.0 & 10 & 25.0 & 10 & 25.0 & 25 & 62.5 & 0 & 0.0 \\
\hline Intensity (3) & 11 & 27.5 & 22 & 55.0 & 0 & 0.0 & 24 & 60.0 & 0 & 0.0 & 14 & 35.0 & 5 & 12.5 & 23 & 57.5 \\
\hline Intensity (4) & 7 & 17.5 & 4 & 10.0 & 0 & 0.0 & 2 & 5.0 & 0 & 0.0 & 16 & 40.0 & 0 & 0.0 & 16 & 40.0 \\
\hline FET & \multicolumn{4}{|c|}{$10.618(.014)$} & \multicolumn{4}{|c|}{$59.636(.000)$} & \multicolumn{4}{|c|}{$60.000(.000)$} & \multicolumn{4}{|c|}{$60.016(.000)$} \\
\hline
\end{tabular}

Note. $\chi^{2}(P)$ : Chi-Square Test $\& P$ for $\chi^{2}$ Test; FET $(P)$ : Fisher Exact Test $\& P$ for FET-Test. *: Significant at $P \leq .05$ 
Table 6 illustrates number and percent distribution of the study and the control groups according to their satisfaction. It was noticed that, mothers among both groups reported moderate satisfaction level with their labor pain intervention in favor of the study group (35\% and $12.5 \%$ ), respectively. In addition, more than one half (55\%) of study group exhibit high satisfaction level compared to none of control group. A highly statistically significant difference was noticed between the study \& control in relation to their satisfaction level where $P=.000$.

Table 6. Number and percent distribution of the study and the control groups according to their satisfaction

\begin{tabular}{|c|c|c|c|c|}
\hline \multirow{3}{*}{ Level of satisfaction } & \multicolumn{4}{|c|}{ Immediately after intervention } \\
\hline & \multicolumn{2}{|c|}{ Study } & \multicolumn{2}{|c|}{ Control } \\
\hline & No & $\%$ & No & $\%$ \\
\hline No satisfaction & 0 & 0 & 25 & 62.5 \\
\hline Mild satisfaction & 4 & 10 & 10 & 25 \\
\hline Moderate satisfaction & 14 & 35 & 5 & 12.5 \\
\hline High satisfaction & 22 & 55 & 0 & 0 \\
\hline FET & \multicolumn{4}{|c|}{$43.535(.000)^{*}$} \\
\hline
\end{tabular}

Note. $\chi^{2}(P)$ : Chi-Square Test \& $P$ for $\chi^{2}$ Test; FET $(P)$ : Fisher Exact Test \& $P$ for FET-Test. *: Significant at $P \leq .05$

\section{Discussion}

Labor pain is a complex phenomenon, and it is known that women's experiences of this pain vary enormously. Labor pain may provoke tension and anxiety. Although pain relief in labor is an important issue in obstetric \& midwifery care; yet, there is no standard and accepted technique for its relief without side effects. Generally, there are two options for pain relief during labor; pharmacological and non-pharmacological methods. Several simple nonpharmacological approaches for the relief of labor pain are now available \& many of them can be initiated by nurses, midwives, obstetricians, and even by the woman herself. Ice application as one of these approaches may improve labor progress; reduce the use of riskier medications, increase parturient coping and satisfaction as well as decrease costs. ${ }^{[29]}$ Hence the present study was conducted to evaluate effect of ice pack application on pain intensity during active phase of the first stage of labor among primiparaous.

The present study indicated that a highly statistically significant difference was observed in labor pain level using VAS among study \& control group before and immediately as well as $30 \& 60$ minutes after ice application, where $P \leq .000$ ) (see Table 4). This was clearly demonstrated when the intensity of labor pain among the study group has changed significantly. Severe pain has sharply declined then completely disappeared immediately and after $30 \mathrm{~min}$ of intervention. This obvious effect was observed in spite of the fact that

Published by Sciedu Press intensity of labor pain usually increases with the progress of labor. Decreased pain intensity among the study group may be largely due to their increased comfort and wellbeing, which are probably endorsed by to the applied intervention. This may be due to that the use of cold application can be a potential solution for the pain management which will help in decreasing giving analgesic effect. It is also fortified by the theory that decreased nerve conduction velocity, attenuation or block of pain conduction to central nervous system via gate control theory, mind deviation from pain, and decreased muscle stretch which all result in increase in pain perception threshold. ${ }^{[30]}$

This result is in accordance with finding of Dehcheshmeh et al. (2009). ${ }^{[31]}$ They found that parturient who had been given ice application experienced highly significant and considerable relief of pain than the control group $(P<.001)$. They concluded that ice application is low risk, low cost and can be easily integrated into nursing practice since cold packs are easily accessible in most hospitals. It is a non-invasiveness technique and safe nursing intervention that can relief pain during first stage of labor with high women satisfaction.

Moreover, the present finding is in conformity with the study of Kaviani et al. (2011), ${ }^{[15]}$ they revealed that the mean intensity of labor pain before and immediately after intervention decreased in the acupressure and ice groups but it increased in the control group $(P<.001)$. The decrease in pain was higher in the ice application group. Furthermore, the current finding is in harmony with the study of Shirvani \& Ganji $(2014)^{[32]}$ who had conducted a randomized controlled trial about the influence of cold pack on labour pain relief and birth outcomes in Iran. They reported that labor pain intensity using VAS was significantly lower in cold therapy group compared with control. Their research also indicated that it has a benefit effect on labour phases without adverse effect on mother and fetal outcomes. Decreased labor pain intensity among the study group in the present study agrees with the study done by Afefy (2015). ${ }^{[33]}$ She reported that statistically significant differences between the three groups regarding pain intensity immediately $(P<.003), 30$ minutes $(P<.002)$, and 1 hour $(P<.02)$ after intervention. She concluded that however pain intensity was increased; ice group had more persistent effects on pain reduction than acupressure group.

It is also in line with a randomized controlled trial done by Vargens, Octavio et al. (2016) ${ }^{[34]}$ who had studied the effects of cryotherapy in relieving childbirth pain in Brazil. Their results revealed that $91.67 \%$ of the participants reported pain relief and better conditions. They also concluded that cryotherapy showed effective in releasing pain in labor, does not affect in the physiological process of childbirth. 
On the other hand, this same present study result disagrees with the findings Shirvani \& Ganji $(2016)^{[35]}$ who had studied the comparison of separate and intermittent heat and cold therapy in labor pain management in Iran. They reported that although it was not significantly different between three groups. Pain intensity was slightly lower in the heat therapy group during labor. This discrepancy in the results may be explained by the use of different methods for ice application in the present study and the contradictory research. Where, the used ice in the present study was ice gel packs compared to and ice bags in Shirvani \& Ganji's study.

The current study assessed the intensity of labor pain before and after ice pack application using two tools. Among these tools is the PBIS which was used to determine the intensity of labor pain by measuring its manifestations. Again, the results of the current study revealed that after 30 and $60 \mathrm{~min}$ utes of ice application an outstanding decline in the intensity of labor pain was monitored as measured by PBIS. This was obviously demonstrated among the study group before and after application of ice application (see Figure $3 \&$ Table 5) i.e. immediately \& 30 minutes after the intervention, none of the study group had either intensity (3) \& (4).

Although, no studies are available to support this result, yet it should be worthwhile to conduct further researches on this virgin area in order to evaluate its effectiveness. However, the study of Capogna et al. (2010) ${ }^{[36]}$ who studied multidimensional evaluation of pain during early and late labor: a comparison of nulliparous and multiparous women in Rome, Italy. They used in which VAS and PBIS evaluate the intensity of labor pain. They concluded that an understanding of labor pain in a multidimensional framework provides the bases for a woman-centered approach to its management.

Additionally, Evaluation of mothers' satisfaction in the present study revealed that a highly statistically significant difference was observed in relation to satisfaction level among study \& control group before \& after intervention. This could be attributed to fact that non-pharmacological methods including cold therapy increased maternal satisfaction by inducing control and empowerment feelings. It also addresses not only the physical sensations of pain, but also attempt to prevent suffering by enhancing the psychoemotional and spiritual components of care. ${ }^{[37]}$

The current finding is relatively in accordance with two studies. First the pervious mentioned study done by Shirvani et al. (2013), ${ }^{[32]}$ which reported that maternal satisfactory rate was higher in cold therapy group compared to control group. Second, Abdel Ghani (2014) ${ }^{[38]}$ who did study about effect of heat and cold therapy during the first stage of labor on women perception of birth experience in Egypt. Her results indicated that, the study group mothers had moderate satisfaction level related to their labor experience with statistical differences in favor of the study group $(P \leq .0001)$.

\section{Conclusion}

Based on the study findings, it could be concluded that the application of ice pack over abdomen and back during active phase of first stage of labor appears to have a remarkable effect on labor pain intensity.

\section{Recommendations}

In-service training programs for nurses in labor units about the utilization of non-pharmacological approaches is recommended. The integrated pain management program should be combined with routine teaching of the Antenatal Care Unit and nursing intervention of the Labor Room.

\section{Conflicts of InTERest Disclosure}

The authors declare that there is no conflict of interest.

\section{REFERENCES}

[1] The world Bank. Birth rate-crude (per 1; 000 people) in Egypt. 2015 Available from: http://www.tradingeconomics.com/egypt/b irth-rate-crude-per-1-000-people-wb-data.htm

[2] UNICEF. Egypt: statistics. December 2013. Available from: http://www .unicef .org/infobycountry/egypt_statist ics.html

[3] Cunningham FG, Bloom SL, Leveno KJ. Williams's obstetrics. 23rd. New York: The McGraw-Hill Companies 2010.

[4] Simposon K, Creehan P. Perinatal Nursing. 4th ed. Philadelphia: Lippincott Williams \& Wilkins. 2014; 343-98.

[5] Rouhe H, Salmela Aro K, Halmesmaki E, et al. Fear of childbirth according to parity, gestational age, and obstetric history. BJOG: An International Journal of Obstetrics \& Gynaecology. 2009; 116: 67-73.
PMid:19055652 https://doi.org/10.1111/j.1471-0528.20 08.02002. $\mathrm{x}$

[6] Hjelmstedt Ay, Shenoy ST. Effect of Acupressure to Reduce Pain During Active Stage Of Labor. Acta Obstetrician et Gynecologica Scandinavica. 2010; 89(11): 1453-1459. PMid:20822474 https: //doi.org/10.3109/00016349.2010.514323

[7] Koji Z, Arsenijevi L, Scepanovi L, et al. Labor pain: physiologic basis and regulatory mechanisms. Srpski Arhiv Za Celokupno Lekarstvo. 2007; 135: 235-9.

[8] Prenatal Yoga Center. The Gate Control Theory of Pain Management in Childbirth and the Epidural. New York. 2009.

[9] Cooper GM, MacArthur C, Wilson MJA, et al. Satisfaction, control and pain relief: short-and long-term assessments in a randomized controlled trial of low-dose and traditional epidurals and a non-epidural 
comparison group. International Journal of Obstetric Anesthesia. 2010; 19: 31-7. PMid:19945274 https://doi.org/10.1016/j . ijoa.2009.05.004

[10] Chaillet N, Belaid L, Crochetière C, et al. Non pharmacologic approaches for pain management during labor compared with usual care: a meta-analysis. Birth. 2014; 41(2): 122-37. PMid:24761801 https://doi.org/10.1111/birt.12103

[11] Williams J, Mitchell M. Midwifery managers' views about the use of complementary therapies in the maternity services. Complementary Therapies in Clinical Practice. 2007; 13: 129-35. PMid:17400148 https://doi.org/10.1016/j.ctcp.2006.01.001

[12] Simkin P, Bolding A. Update on non-pharmacologic approaches to relieve labor pain and prevent suffering. Journal of Midwifery \& Women's Health. 2004; 49(6): 1-3. PMid:15544978 https: //doi.org/10.1016/j.jmwh.2004.07.007

[13] Deepak, Avanish R, Seema CH. Effect of acupressure on intensity of labor pain and duration of first stage of labor among primigravida mothers. Nursing \& Midwifery Research J. 2013; 9(4): 178-189.

[14] Hosseini E, Asadi N, Zareei F. Effect of massage therapy on labor progress and plasma levels of cortisol in the active stage of first labor. Zahedan J Res Med Sci (ZJRMS). 2013; 15(9): 35-38.

[15] Kaviani M, Ashoori M, Azima S, et al. Comparing the effect of two methods of acupressure and ice massage on the pain, anxiety levels and labor length in the point LI-4. Journal of ShahidSadoughi University of Medical Sciences. 2012; 20(2): 220-22.

[16] Salehian T, Safdari Dehcheshmeh FS. Effects Of Acupressure at The Sanyinjiao Point (Sp6) on Labor Pain and Delivery Time in Nulliparous Women. Shahrekord University of Medical Science J. 2011; 12(4): 8-14.

[17] LATHA K. Effectiveness of Ice Massage on Li4 Acupressure Meridian Point in Labour pain Perception among the Parturient Mothers. Int J Pharm Bio Sci. 2016; 7(2): 326-332.

[18] Algafly AA, George KP. The effect of cryotherapy on nerve conduction velocity, pain threshold and pain tolerance. Br J Sports Med. 2007; 41(6): 365-369. PMid:17224445 https://doi.org/10.1 136/bjsm. 2006. 031237

[19] Maciel L, Ferreira J, Santos Heleodorio HD, et al. Effects of transcutaneous electrical nerve stimulation and cryotherapy on pain threshold by induced pressure. J Fisioterapia e Pesquisa. 2014; 21: 249-256.

[20] Herrera E, Sandoval MC, Camargo DM, et al. Motor and sensory nerve conduction are affected differently by ice pack, ice massage, and cold water immersion. Phys Ther. 2010; 90(4): 581-591. PMid:20185615 https://doi .org/10.2522/ptj . 20090131

[21] Kimberly K. The neuromatrix theory of pain: Implication for selected non-pharmacologic methods of pain relief for labor. Midwifery and Women Health. 2004; 49(16): 482-488.

[22] Golda M, Revathi D, Subhashini N, et al. Assess the effectiveness of cold application on pre procedure (AV fistula puncture) pain among hemodialysis patients in tertiary care hospital, Nellore. International Journal of Applied Research. 2016; 2(6): 660-664.

[23] Sinha RV, Dave K, Goyal H, et al. Effects of cold application on pain $\&$ anxiety during chest tube removal among post operative cardiac surgery adult patients. IOSR Journal of Nursing and Health Science. 2016; 4(6): 64-68.

[24] de Souza Bosco Paiva C, Junqueira Vasconcellos de Oliveira SM, Amorim Francisco A, et al. Length of perineal pain relief after ice pack application: A quasi-experimental study. Women Birth. 2016; 29(2): 117-22. PMid:26395154 https://doi.org/10.1016/j. wombi.2015.09.002

[25] Melzac R, Katz J. Pain measurement in persons in pain. In: Wall P, Melzac R. Textbook of pain. London: Churchill Livingstone. 1994. 337-51.

[26] Bonnel AM, Boureau F. Labor Pain Assessment: Validity of a behavioral Index. Pain. 1985; 22(1): 81-90. https ://doi.org/10.101 6/0304-3959 (85) 90150-2

[27] Brokelman RBG, Haverkamp D, Veth R. The validation of the visual analogue scale for patientsatisfaction after total hip arthroplasty. Eur J Orthop Surg Traumato. 2012; 13(2): 101-105.

[28] Pasero C, McCaffery M. Superficial cooling for pain relief. The Am Journal of Nursing. 1999; 99: 24.

[29] Hajiamini Z, Masoud NS, Ebadi A, et al. Comparing the Effects of Ice Massage and Acupressure on Labor Pain Reduction. Complementary Therapies in Clinical Practice. 2012; 18: 169-17. PMid:22789793 https://doi.org/10.1016/j.ctcp.2012.05.003

[30] Roberts L. The Coping With Labor Algorithm: An Alternate Pain Assessment Tool For Laboring Woman. Journal of Midwifery and women's health. 2009; 55(2): 107-116. PMid:20189129

[31] Dehcheshmeh FS, Delaram M, Salehian T, et al. Relief of Labor Pain By Ice Massage of The Hand. Zahedan Jourdan of Research in Medical Sciences. 2009; 11(10): 23-29.

[32] Shirvani MA, Ganji Z. The influence of cold pack on labour pain relief and birth outcomes: a randomised controlled trial. J Clin Nurs 2014; 23(17-18): 2473-9. PMid:24206010 https ://doi .org/10 $.1111 /$ jocn. 12413

[33] Afefy N. Effect Of Ice Cold Massage And Acupressure On Labor Pain And Labor Duration: A Randomized Controlled Trial in Cairo. Journal of Natural Sciences Research. 2015; 5(22): 137-43.

[34] Vargens Octavio MC. Nunes, Sonia, da SilvaLolita D, Progianti, Jane M. Pain Relief Effect of Cryotherapy in Parturients. 2016; 6(3): 149-156.

[35] Shirvani M, Ganji J. Comparison of separate and intermittent heat and cold therapy in labour pain management. Nurs Pract Today. 2016; 3(4): 179-186.

[36] Capogna G, Camorcia M, Stirparo S, et al. Multidimensional evaluation of pain during early and late labor: a comparison of nulliparous and multiparous women. Int J Obstet Anesth. 2010; 19(2): 167-70. PMid:20219349 https://doi.org/10.1016/j.ijoa.2009.05 .013

[37] Leifer A. Burroughs Maternity nursing: an introductory text. Elsevier/Saunders. 2005.

[38] Abdel Ghani R. Effect of Heat and Cold Therapy during the First Stage of Labor on Women Perception of Birth Experience: A Randomized Controlled Trial. Journal of Biology, Agriculture and Healthcare. 2014. 